Walker, N. (1978) Dangerous people. International Journal of Law and Psychiatry, 11, 37-50.

West Midlands RHA (1991) Report of the panel of inquiry appointed to investigate the case of Kim Kirkman.

\section{Multiple choice questions}

1 Risk assessment:

a Does not need to be documented

b Allows the avoidance of all risks

c Simply involves stating that a risk exists

d Is the subject of Department of Health guidelines

e Does not rely solely on the history from the patient

2 An individual patient's risk of harm to others:

a Can be more reliably assessed with collateral information

b Depends almost always on actuarial factors, not on an individual patient's history

c Will be abolished by sucessful treatment of any mental illness

d Is usually related to situational factors as well as to the patient's disorder

e Is almost always the reflection of an inherent and immutable quality in an individual

3 A psychotic patient prior to admission threatens and assaults his mother. On the ward he makes verbal threats towards almost all the staff and patients:

a He only poses a risk of actual harm to his mother whom he had assaulted

b You should not assume his risk of violence arises solely from the psychotic illness

c He threatens all the staff and patients and so poses some risk of harm to all of them

d He will only pose a risk to more mature female staff e You need more information to assess the future risk he may pose to others

4 A patient holding a kitchen knife is hurrying down a hospital corridor, seeming to chase after another patient walking ahead. A nurse asks him to stop. He hands over the knife without complaint:

a He poses much less risk of harm than another patient who punched a nurse

b He has not yet been violent but he does pose a significant potential risk of violence

c He may pose a risk to someone other than the patient he was following

d He will not pose a risk if he is routinely observed

e He will not pose a risk if he has routine access to the ward kitchen

5 Psychiatrists should routinely consider:

a Asking the patient about any history of violent acts

b Asking the patient about thoughts or fantasies of violence

c Trying to ask an informant about any history of patient violence

d Requesting previous discharge summaries

e Documenting the responses to a-d even if negative

MCQ answers

$\begin{array}{lllll}1 & 2 & 3 & 4 & 5\end{array}$

a $F$ a $T$ a $F$ a $F$ a $T$

b F b F b T b T b T

c $F$ c $F$ c $T$ c $T$ c $T$

d $T$ d $T$ d F d F d $T$

e $T$ e $F$ e $T$ e $F$ e $T$

\title{
Continuing Professional Development
}

\section{Validation}

From 1 January 1996, the application form for the validation of all CPD events will be available on request from the College. Completed forms relating to national or international CPD events should be returned to the College to be processed. Completed forms relating to regional or local events should be returned to the CPD Deputy Regional Adviser (details available on the application form).

For more information please contact Mrs Jean Wales, CPD Officer or Ms Pauline Taggart, CPD Administrator at The Royal College of Psychiatrists, 17 Belgrave Square, London SW1X 8PG. Tel: 0171235 2351 extension 270 or 112. 